\title{
ENTREVISTA COM MOACIR PALMEIRA
}

\author{
José Sergio Leite Lopes \\ Museu Nacional/Universidade Federal do Rio de Janeiro - Brasil
}

\section{Introdução}

Esta entrevista com Moacir Palmeira foi editada a partir de um depoimento em uma sessão do curso "Etnografias em situação de dominação social”, ministrado por mim no primeiro semestre de 2012 no Programa de Pós-Graduação em Antropologia Social do Museu Nacional da Universidade Federal do Rio de Janeiro (PPGAS-MN/UFRJ). No dia 17 de maio de 2012 Moacir Palmeira, Beatriz Heredia e eu demos um depoimento para uma turma de estudantes de pós-graduação sobre nossa participação nos projetos de pesquisa relativos à plantation canavieira no Nordeste, e seus desdobramentos. Aqui foi mantido o depoimento de Moacir Palmeira para efeitos desta edição.

A entrevista-depoimento abrange as pesquisas iniciais de Moacir Palmeira partindo do projeto sobre os processos de transformação social da plantation canavieira na Zona da Mata de Pernambuco e chegando aos desdobramentos realizados através do projeto "Emprego e mudança social do Nordeste" que continuaram tendo efeitos muitos anos após o seu término. Coordenador das pesquisas coletivas que tiveram lugar durante esses projetos, as dissertações e teses que dali resultaram produziram efeitos inovadores em várias frentes do campo antropológico e das ciências sociais.

Em particular, a consideração desta linha de pesquisa e seus desenvolvimentos ao longo do tempo trouxe contribuições nos últimos anos para a área do que chamamos "antropologia do trabalho” em alguns GTs da Associação Brasileira de antropologia (ABA) e da Reunião de Antropologia do Mercosul (RAM) que têm atraído trabalhos de várias partes do sistema universitário de pós-graduação em ciências sociais, e que têm também expressado, em particular, uma colaboração entre as linhas de pesquisa sobre trabalho e 
cidade existentes no Programa de Pós-Graduação em Antropologia Social da Universidade Federal do Rio Grande do Sul (PPGAS-UFRGS), no interior do Banco de Imagens e Efeitos Visuais (Biev), bem como no PPGAS-MN/UFRJ, colaboração esta que também se corporifica neste número de Horizontes Antropológicos. De fato, o ressurgimento dessa temática se dá num período de fortes transformações econômicas e sociais fazendo dispersar as configurações sociais que envolviam os trabalhadores e suas famílias: a reunião de novos estudos sob o recorte do trabalho e seus efeitos sobre a constituição da sociabilidade pode ser interessante para o mapeamento de mudanças e permanências. Tais transformações nos levaram a procurar desconstruir e dessubstancializar categorias tão carregadas de significados, como as de "classe trabalhadora", através da análise da sua construção social, histórica e intelectual, dando-se importância também à análise dos mediadores associados àquelas classes. Por outro lado o próprio obscurecimento das faces públicas dos trabalhadores, através de renomeações e reclassificações nas empresas que procuram atingir suas anteriores identidades, pode ser um estímulo adicional para essa reunião de estudos em andamento. De certa forma o trabalho pode ser visto, assim, de forma mais ampla, desde as fronteiras da informalidade urbana até novas formas de profissionalização de atividades anteriormente vistas como de "lazer”. As relações entre família e trabalho podem se constituir em outro eixo de reunião de resultados de pesquisa; assim como a relação com o "lazer", que vai desde o trabalho subsidiário ou a bricolagem e o trabalho doméstico até atividades religiosas, esportivas ou de cultura popular. Assim como da relação do trabalho com a educação ou com a relativamente nova temática do meio ambiente, do risco industrial e da saúde do trabalhador. Além disso, as transformações na agricultura e a teia social que se arma por baixo do agronegócio levam os estudiosos do campesinato a se reaproximarem da temática do trabalho e a trocarem experiências com pesquisadores de outros setores econômicos e sociais. E a marca do trabalho na paisagem e na memória social nas grandes cidades, antes mais direta, apresenta novas características que vêm sendo estudadas.

Parece-me que a recuperação da experiência de pesquisa que Moacir Palmeira promoveu desde o início dos anos 1970 é sugestivamente inspiradora dessa retomada de novos estudos. A entrevista a seguir procura dar elementos para contextualizar tal experiência. O universo da plantation açucareira, com sua dinâmica envolvendo trabalho e instabilidade do trabalho; dominação 
pessoal e idealização do passado; imobilização da força de trabalho e novas mobilidades; barracão e feira; produção e mercado; família e terra de trabalho; migração sazonal, migração de longa distância e volta à origem e acesso ao roçado; direitos e conflitos, é um universo de transformações paradigmático dessa imersão do trabalho na teia da vida social. Também sua extensão posterior, por meio de projetos maiores envolvendo áreas mais amplas do Nordeste, do Norte e das grandes cidades, estenderam espacialmente os estudos iniciados na área da plantation. Depois, em período mais recente não coberto pelo presente depoimento, Moacir Palmeira e Beatriz Heredia promoveram pesquisas sobre a chamada antropologia da política, com ênfase na etnografia das concepções nativas da política em populações rurais e urbanas. E voltaram ao universo do trabalho pela via do estudo dos assentamentos rurais, por um lado, e pelo estudo da sociedade que subjaz ao agronegócio, por outro.

É a experiência inicial dessa trajetória e sua contextualização que esta entrevista-depoimento nos traz.

Esta entrevista contou, para a sua edição, com a colaboração de Anelise Gutterres, doutoranda do PPGAS-UFRGS.

\section{Entrevista}

Antes de o gravador ser ligado, sugeri que Moacir Palmeira iniciasse seu relato desde o contexto de seu contato inicial com as ciências sociais no curso de graduação da Escola de Sociologia e Política da PUC-RJ, onde tinha por colegas de turma, entre outros, Otávio Velho e Luiz Antonio Machado da Silva.

Moacir Palmeira: Nós vínhamos da Escola de Sociologia e Política da PUC-RJ, do curso de sociologia de lá. Para mim e alguns colegas meus, isso foi intercalado com um curso na Bahia, na época um curso de especialização de ciências sociais dirigido pelo Thales de Azevedo, e que devia ser uma experiência de vanguarda. Na época a Cepal, Comissão Econômica para a América Latina, estava dando curso de economia, no Chile, e, depois, começou a implementá-lo, junto com a Sudene [Superintendência do Desenvolvimento do Nordeste], no Brasil. Tratava-se de tentar fazer nas ciências humanas e sociais o que vinha sendo feito pela Cepal e Sudene. Na época Celso Furtado e Oswaldo Sunkel queriam renovar os cursos de especialização para a economia. 
Os cursos na universidade tinham predominância dos neoclássicos e não serviam para os desenvolvimentistas. E no curso de ciências sociais a ideia era fugir dos moldes tradicionais.

Para vocês terem uma ideia eu entrei na PUC-RJ e eu tive no meu primeiro ano 12 matérias, tinha tudo o que se possa imaginar. Já nesse período de faculdade havia as lutas políticas, o movimento estudantil. Tínhamos interesse, na época, na militância estudantil, essa coisa toda, e o acompanhamento da situação nacional. Todo esse grupo que hoje está aí, o Otávio Velho foi meu colega, o Luiz Antônio Machado da Silva foi meu colega de curso, depois outros, de outras turmas, um pouco acima, um pouco abaixo. A Lygia Sigaud (também professora do Museu) estava fazendo o primeiro ano, enquanto eu, Otávio, Machado, estávamos fazendo o último ano da faculdade, e uma série de pessoas. ${ }^{1}$ Então havia, digamos, de um lado a preocupação teórica, marcada pela teoria marxista, e por outro lado uma atitude dessa nossa turma, que logo no inicio da escola assumiu muito a postura profissionalizante. Tanto que nós pressionamos a direção (e tivemos sucesso) da Escola de Sociologia a adotar o sistema de créditos, para liquidar com essa historia de 12 cursos. Éramos desde o início muito ligados a essa ideia da pesquisa científica, preocupados em saber como iríamos casar a pesquisa empírica com as grandes elaborações teóricas do marxismo e de outras teorias, falando assim grosseiramente para não perder tempo.

Logo nos primeiros anos da Escola de Sociologia e Política partimos para o trabalho de campo, para uma pesquisa sobre o retorno de migrantes nordestinos para os seus locais de origem, pesquisa do padre Fernando Bastos de Ávila. Ficamos um mês, Sergio Lemos, que tinha uma liderança intelectual sobre o grupo, Otávio Velho, Machado da Silva, Francisco Paiva Chaves e eu, rodando pelo interior de Alagoas. Foi uma experiência muito interessante.

Esse interesse pela pesquisa nos levou a trabalhar em várias outras pesquisas quando voltamos ao Rio de Janeiro, depois dessa primeira viagem a campo.

Para ganhar experiência aplicamos os questionários do Ibope [Instituto Brasileiro de Opinião Pública e Estatística]. Por outro lado, fizemos pesquisas

1 Para outros depoimentos sobre essa mesma turma de colegas, ver "Entrevista com Luiz Antonio Machado da Silva” (2010); ver também Palmeira (2006). 
aqui em várias favelas do Rio com Gláucio Ary Dillon Soares e Geraldo Semenzato (Guararapes, no Cosme Velho, Rocinha, Praia do Pinto, Parque Proletário da Gávea). Gláucio, que estava voltando dos EUA onde tinha trabalhado com Seymour Lipset, era tido como empiricista. Mas ele foi realmente decisivo para nós; muito disciplinado, dava seminários à noite nas nossas casas, na casa de um, na casa de outro, nós aprendemos com ele técnicas avançadas e métodos quantitativos e coisas dessa ordem. E o Geraldo Semenzato, que tinha acabado de deixar a direção da Revista de Sociologia ligada à Escola de Sociologia e Política de São Paulo e que entre outras coisas tinha sido assistente do Alceu Maynard Araújo naquela pesquisa do Donald Pierson, sobre o Vale do São Francisco.

Foi Semenzato quem nos motivou para o curso de treinamento básico em ciências sociais na Bahia. Sergio Lemos, Otávio, Machado e eu fizemos o concurso de seleção e passamos todos, embora Otávio tenha preferido ficar no Rio. O curso era uma espécie de mestrado concentrado, mas como eles não conseguiram gente já formada, abriram para quem estava fazendo a graduação. Ficamos então entre julho de 1962 e julho de 1963 em Salvador, vindo ao Rio fazer as provas em segunda chamada na PUC-RJ. O curso na Bahia exigia dedicação plena, das oito da manhã às seis da tarde. No final do curso tínhamos que apresentar uma monografia. Escrevi a monografia "Banditismo político e estrutura social”, sobre banditismo político no Nordeste, em Alagoas. Eu não entendia por que as Ligas Camponesas nunca haviam entrado em Alagoas. As Ligas tinham se espalhado pelo Nordeste todo. Em Pernambuco, na Paraíba eram fortíssimas, na Bahia e Sergipe já estavam começando. No meu estado [Moacir é originário de Alagoas] a violência política a serviço de chefes políticos então era regra. Na base desse trabalho havia portanto uma preocupação com o movimento camponês. ${ }^{2}$

Na Bahia nós tivemos oportunidade também de fazer trabalho de campo. Participamos de uma pesquisa para o Cida, Comitê Interamericano de Desenvolvimento Agrícola, e eles faziam estudos de comunidade em vários países; no Brasil acho que foram feitos 11 estudos, e na Bahia ia se estudar a área do cacau e o Recôncavo Baiano. No Recôncavo ainda estava começando a ser instalado o polo de Camaçari, que virou um dos grandes centros

2 Essas preocupações estão presentes no seu primeiro artigo publicado; ver Palmeira (1966). 
industriais do país. Então eu fui para essa área de Camaçari. Ficamos cerca de um mês em campo, seguimos lá dormindo na casa de um camponês, eu e o Machado. O Sergio Lemos foi para o sul, para o cacau com o Semezato, e nós fomos com a Maria Brandão para Camaçari.

De volta ao Rio, depois vivíamos aí pegando bicos, para trabalhar em pesquisas que duravam três, quatro meses, com o Candido Mendes. Ele tinha sido nosso professor, e foi importante para nós. Participamos de uma pesquisa sobre a mão de obra na indústria química. Mas, sobretudo no caso meu e do Otávio, lá no Centro Latinoamericano de Pesquisas em Ciências Sociais (Clapcs), instituição que fazia parte de um trio com a Flacso do Chile, a Faculdade Latino-Americana de Ciências Sociais, e com o Conselho Latino Americano de Ciências Sociais, em Buenos Aires... ensino no Chile, pesquisa aqui e coordenação em Buenos Aires. Que era um acordo da Unesco [Organização das Nações Unidas para a Educação, a Ciência e a Cultura] com os governos latino-americanos. Era o Manuel Diégues Junior que dirigia o Clapcs (depois do mandato de Luiz Costa Pinto). Diegues foi nosso professor na PUC-RJ, então, nós começamos a trabalhar em pesquisa naquele centro.

E no Centro Latino-Americano apareceu um convite para participar de um projeto de pesquisa no exterior. Aí nos candidatamos eu e o Otávio Velho, assim como Rosa Maria Ribeiro da Silva, que era também colega de faculdade, e com quem depois eu fui casado, e daí ganhamos essas bolsas. O Otávio preferiu não ir.

Na mesma época estávamos tentando ir para a Flacso, no Chile; passamos, mas eu optei pela França, para fazer uma pesquisa. Não queria ficar mais de um ano fora em hipótese alguma porque estava ligado nas coisas políticas daqui. E lá, no primeiro contato que tive com a figura que depois foi ser meu orientador [François Bourricaud], constatei que ele nada sabia disso: "que pesquisa?”. Era uma pesquisa inexistente. Eu falei com o Pierre Monbeig que era o presidente do Instituto da América Latina [da Universidade de Paris]. Ele pediu desculpas e disse que não havia a linha de pesquisa anunciada, o projeto não tinha sido implementado.

O Pierre Monbeig, que era uma figura realmente extraordinária - eu me arrependo de não ter aproveitado mais a convivência com ele - insistiu para que eu fizesse o doutorado. Era um período longo, de modo que, enquanto decidia eu preferi ficar fazendo seminários - na École Pratique des Hautes Études e no próprio Instituto da América Latina - até decidir me inscrever 
para o doutorado. Bom, o projeto que eu tinha apresentado, "Implicações políticas do desenvolvimento do capitalismo no campo”, estava de acordo com as preocupações da época. Havia uma grande discussão em torno disso, e tentei começar a trabalhar o tema, através de um trabalho sobre as condições emergentes da vida camponesa. Acontece que uma colega, Aspásia Camargo, tinha também uma pesquisa nessa direção e estava mais adiantada, já tinha feito entrevistas com lideranças que haviam atuado no movimento camponês e que estavam no exílio, no exterior. Preferi então tentar dar conta do debate em torno da natureza das relações sociais no campo no Brasil desde o período colonial; sobre as relações feudais, semifeudais, escravistas, capitalistas, que teriam existido ou continuariam existindo no Brasil. Então eu comecei a mexer com isso, já tinha um investimento anterior e passei a explorar essa via. Logo depois, percebendo que não era possível fazer pesquisa empírica no Brasil, aquele debate foi tomado como o próprio objeto da tese. Acho que foi uma boa coisa: os trabalhos sobre produção intelectual, as análises semiológicas estavam no ar em Paris. Mas eu fui me aproximando muito das formulações do Bourdieu e algumas do Althusser, que acabaram sendo as principais referências teóricas de minha tese.

Eu voltei para o Brasil em 1969 com a tese entregue, mas ela só pôde ser defendida em $1971 .^{3}$ Na tese eu estava questionando uma coisa que me incomodava, os argumentos no fundo eram os mesmos dos dois lados. Eu havia notado que um dos autores argumentava em favor da existência do capitalismo escravista no Brasil. Mas depois, numa nova edição do livro, o partido que apoiava, havendo mudado de posição, ele passara a defender a tese do feudalismo, mantendo a mesma argumentação anterior. Havia evidentemente um jogo político envolvendo o exercício da argumentação. Sem prejuízo do trabalho de pesquisa e dos argumentos interessantes com os quais os autores produziam.

Então, lendo isso, me apropriando desse material, me pareceu que a noção de plantation poderia contribuir nesse debate. Porque ao mesmo tempo em que se falava de capitalismo, modernização, nas áreas de cana-de-açúcar no Nordeste, era também sobre essas áreas que mais incidia essa ideia de um semifeudalismo, de restos feudais. O barracão, o uso de vales na remuneração

3 Ver Palmeira (1971). 
dos trabalhadores rurais, os dias de trabalho gratuito eram vistos por alguns como eventuais resíduos feudais, enquanto outros diziam que se tratava de um capitalismo escravista, ou algo do gênero. Lendo esse material, me pareceu que havia uma certa sistematicidade nesses elementos e então apostei na especificidade da plantation. O que aconteceria se nós considerássemos a plantation como um modo de produção específico, ainda que subordinado. Então a tese ia por aí, mas a minha ideia era ver empiricamente como isso se dava.

Havia indicações no trabalho de um geógrafo francês, Patrick Calamart du Genestoux, ${ }^{4}$ que fez um belo trabalho sobre a Zona da Mata de Pernambuco, que apontava o crescimento das feiras na área canavieira; e eu associei isso a um trabalho de Sidney Mintz que eu havia lido sobre praças de mercado na Jamaica - essas feiras que teriam surgido com a venda de produtos por escravos fugidos e que ajudaram a minar o centro escravista naquele país. Pareceume que a competição das feiras com os barracões fosse um bom caminho para pensar as transformações na plantation tradicional. Percebi nas informações que eram dadas no trabalho de Genestoux, e em outros trabalhos, que não teria havido simplesmente uma proletarização dos moradores. Ao lado desse processo de proletarização havia também moradores que tinham virado pequenos produtores. O antigo morador teria dado lugar de um lado ao proletário rural; mas também a um camponês, no sentido de um pequeno produtor com alguma autonomia, de outro.

Eram questões desse tipo que estavam na minha cabeça quando Roberto Cardoso de Oliveira me convidou, por sugestão de Otávio Velho, para participar do projeto "Estudo comparativo do desenvolvimento regional”. Cardoso me chamou para ser uma espécie de coordenador de campo do Nordeste. A Francisca Vieira Keller era quem coordenava as pesquisas do Brasil Central. Vários dos pesquisadores no Nordeste, como Neuma Aguiar, Roger Walker (ambos estudavam o sertão cearense; ela estudava o projeto Asimov; ele, preocupado com relações de arrendamento e parceria) e Stela Amorim (que estudava a nova elite burocrática do Nordeste, surgida a partir da Sudene), tinham mais experiência de pesquisa do que eu. Então não tinha muito o que coordenar. Mas eu senti que o Roberto queria que eu tentasse discernir uma problemática comum e criasse um polo de pesquisa que atraísse mais estudantes.

4 Ver Genestoux (1967). 
Então terminou sendo um gerenciamento burocrático dos pesquisadores no período que o Roberto Cardoso esteve nos Estados Unidos; mas comecei ao mesmo tempo a montar um grupo para estudar a zona canavieira. Eu percebi que algumas pessoas, como a Lygia Sigaud, por exemplo, tinham se interessado pela área canavieira assim como Andrea Loyola (mas que logo depois passou a estudar a indústria têxtil em Juiz de Fora, MG). Começando eu a dar aulas no PPGAS-MN/UFRJ, outros alunos mostraram-se interessados em fazer pesquisa na região. Era a oportunidade de pensar a plantation e suas transformações levando em consideração, nos termos de Bourdieu, todo o conjunto de posições e oposições sociais ali presentes.

Já tinha percebido que não se podia pensar a plantation apenas pelo seu lado agrícola. Nas primeiras idas ao campo percebi também que não podia pensar o lado agrícola apenas com o senhor de engenho e os moradores. Havia outras figuras, como os trabalhadores corumbas, que vinham do Agreste para trabalharem na safra, até os trabalhadores da rua. Esta última figura, o trabalhador da rua, era o trabalhador expulso ou o morador entre uma morada e outra, residindo naquelas pequenas cidades do interior. Já estavam surgindo algumas vilas só de trabalhadores da rua. Além deles existia a figura do usineiro, proprietário das usinas, a quem estava subordinado esse senhor de engenho, como fornecedor de cana. Se contrapondo aos usineiros havia os operários da parte industrial da usina. E, entre usineiros e operários, tal como senhores de engenho e moradores, havia os empregados, que eram os funcionários da usina e dos engenhos que de fato eram responsáveis pela organização do trabalho. Entre os engenhos e os seus trabalhadores da rua era cada vez mais presente a figura do empreiteiro, que arregimentava a mão de obra temporária. Mas havia mais: havia os antigos lavradores, àquela altura uma minoria, que eram pequenos produtores de cana que forneciam para a usina e trabalhavam com a família, às vezes passando pela mediação do senhor de engenho. Dentro dos engenhos, ao lado do morador comum, havia a figura do morador foreiro, que explorava o seu sítio com alguma autonomia, pagando um foro anual. E num passado ainda recente, os dias de cambão. O processo de afirmação das usinas e de decadência dos antigos engenhos de açúcar tinha levado os antigos senhores de engenho a venderem ou a arrendarem as suas terras em parcelas. $\mathrm{O}$ que abriu para os moradores expulsos, em alguns casos, uma alternativa à ida para a rua, surgindo algum espaço para pequenos proprietários e arrendatários. 
Considerando a complexidade desse quadro, estabelecemos uma divisão do trabalho no grupo que criamos. José Sergio Leite Lopes assumiu a tarefa de estudar a parte industrial das usinas, tendo feito pesquisa em duas unidades em áreas diferentes do estado. Lygia Sigaud, orientada de David Maybury-Lewis, interessada naquele momento por representações e classificações, centrou seu trabalho sobre moradores e trabalhadores da rua. ${ }^{5}$ Beatriz Heredia, na Mata Norte, e Afrânio Garcia Jr., na Mata Sul, centrariam suas pesquisas nos pequenos proprietários e arrendatários. E Roberto Ringuelet ocupou-se do estudo dos corumbas. ${ }^{6}$

Como as tensões sociais entre, de um lado, usineiros e senhores de engenho, e, de outro, os trabalhadores em geral, eram muito fortes, ficava impossível trabalhar nas duas frentes ao mesmo tempo. Ficou acertado que David Maybury-Lewis, que tinha uma pesquisa com as elites pernambucanas, cobriria usineiros e senhores de engenho. O David, junto com Roberto Cardoso, dirigia o projeto "Desenvolvimento regional comparado". Se esse projeto cobria todas as posições sociais conhecidas, nossa preocupação também era sobre as oposições.

Em 1971, com Shelton Davis, que havia feito sua tese de doutorado na Guatemala, ${ }^{7}$ demos um curso no Programa sobre a problemática da resolução de conflitos, sobre a qual tanto ele quanto eu estávamos interessados. Uma das alunas, Vera Echenique, decidiu trabalhar sobre as tensões e conflitos (trabalhistas ou em torno da terra) que ocorriam na Zona da Mata pernambucana. Concentrou sua atenção sobre os foreiros, que sofriam um processo massivo de expulsão. Um colega seu, Luiz Maria Gatti, se propôs estudar os sindicatos que continuavam atuantes apesar da atuação repressiva do governo e dos proprietários. Infelizmente esse trabalho foi interrompido nesse momento. ${ }^{8}$ Mas a problemática do conflito continuou sendo tocada por todos os pesquisadores citados, assim como por pesquisadores que mais adiante se juntariam ao grupo, como Moema Marques, orientada por Lygia Sigaud, que pesquisou as

\footnotetext{
Ver Sigaud (1979a, 1979b).

Ver Ringuelet (1977).

7 Ver http://en.wikipedia.org/wiki/Shelton_H._Davis. Sua tese de doutorado defendida em 1970 foi publicada em 1997 como La tierra de nuestros antepasados: estudio de la herencia y la tenencia de la tierra en el altiplano de Guatemala (Davis, 1997).

8 O que não impediu que os dois pesquisadores tivessem contribuído para o projeto. Conferir Gatti e Echenique (1974).
} 
Juntas de Conciliação e Julgamento na Mata Sul de Pernambuco, no que diz respeito aos processos trabalhistas.

Por outro lado, o meu próprio subprojeto estava voltado para a oposição e competição entre os barracões de engenho - esse sistema de distribuição interno aos engenhos - e as feiras livres. Chegando a campo vi que a coisa era mais complicada. As usinas tinham não só um barracão, mas um sistema de barracões: um barracão central que vendia para os operários e distribuía para os barracões dos engenhos da usina. Esse sistema de barracões usava mais os vales do que os engenhos particulares, e o dinheiro pouco circulava. Surpresa maior ainda, nós encontramos também feiras dentro de usinas, conhecidas como bacurau. Os barracões de usinas foram incorporados na pesquisa de Sergio Leite Lopes sobre os operários das usinas e sobretudo no meu projeto sobre os barracões e feiras. O bacurau tornou-se objeto de estudo de MarieFrance Garcia. O bacurau, feira que começava à noite e cuja designação está associada ao pássaro noturno, mostrou-se o momento que não só os moradores e o usineiro se encontravam mas vinham também os pequenos produtores autônomos do Agreste e também os intermediários. ${ }^{9} \mathrm{O}$ que sugeria que a forma de dominação com a qual estávamos lidando era muito mais complexa.

Uma surpresa equivalente foi descobrir vilas, vilas no sentido oficial, cabeças de distrito, dentro de fazendas. Primeiro, um caso curiosíssimo, um lugar chamado Bem-Te-Vi, onde a usina comprou todas as terras em torno, derrubou as casas particulares que existiam e plantou tudo de cana: então ficaram os cinco prédios públicos obrigatórios (cartório, escola pública, de três a cinco instituições públicas no meio do canavial), como uma vila-fantasma no meio do canavial. Ainda na área perto de Palmares, que era o centro maior da Mata Sul, e vizinho a uma pequena área de pequenos produtores, nós encontramos uma vila, com cartório, escola e com feira semanal dentro do engenho. Essa vila seria estudada, já numa segunda etapa do projeto, por Doris Rinaldi.

Pegamos esse conjunto de exceções e paradoxos e incentivávamos pesquisadores a trabalharem esses casos, muitos deles tendo por efeito complexificar aquilo a que já me referi como a história da suposta passagem dos barracões às feiras. Doris Rinaldi iria fazer um estudo de comunidade nessa vila que mencionamos e outras dimensões apareceram: a terra da vila era terra

9 Ver Garcia (1977). 
de santo, e era objeto de disputa entre seus habitantes e o dono do engenho onde estava situada. ${ }^{10}$

Ainda na esfera da distribuição nos deparamos com iniciativas dos sindicatos que, buscando oferecer aos trabalhadores alternativas aos barracões, haviam criado cooperativas de consumo. De fato, além da competição intencional com os barracões aparecia uma competição destas cooperativas com as feiras. Para dar conta dessas questões, Leilah Landim investiu sobre o tema e produziu uma interessante dissertação de mestrado. ${ }^{11}$

Esse projeto inicial não acabou, foram sendo abertas novas frentes, novas dissertações foram sendo defendidas e fomos consolidando uma equipe. Fomos fortalecendo os contatos, no próprio PPGAS-MN/UFRJ, com o grupo de pesquisadores em torno de Otávio Velho, equipe que depois participou do projeto sobre hábitos alimentares no Norte do país. E também com um grupo de ex-alunos que foram chamados para colaborar com o IBGE [Instituto Brasileiro de Geografia e Estatística] que então constituía um grupo de indicadores sociais.

Depois houve um período em que tivemos um debate intenso com o pessoal do Cebrap [Centro Brasileiro de Análise e Planejamento] de São Paulo, que foi criado em 1969 e estava no auge em meados dos anos 1970. Tivemos uma série de debates com eles; naquele momento seus pesquisadores contribuíam com pesquisas originais e na militância política. ${ }^{12}$ E no exterior ampliamos em meados dos anos 1970 a relação que eu havia estabelecido com os pesquisadores coordenados, no Centre de Sociologie Européenne, por Pierre Bourdieu, quando assistia seus seminários no meu período de doutoramento na França.

10 Ver Rinaldi (1978).

11 Ver Landim (1978).

12 Essas discussões entre pesquisadores do PPGAS-MN/UFRJ e do Cebrap ocorreram em 1974 e 1975. Em 1974 Otávio Velho apresentou sua tese de doutorado, defendida na Universidade de Manchester em 1973, no Cebrap. Graças a essa discussão (e a uma outra na Unicamp), Otávio Velho foi convidado a publicar sua tese na coleção “Corpo e alma do Brasil” então dirigida por Fernando Henrique Cardoso na Difel, Capitalismo autoritário e campesinato (Velho, 1976). Em 1975 José Sergio apresentou sua dissertação para discussão no Cebrap. Tais discussões em São Paulo eram acompanhadas por delegações de pesquisadores do PPGAS-MN/UFRJ. Sua dissertação “O vapor do diabo”, depois de renhido debate, foi indicada para publicação por Juarez Brandão Lopes, integrante de coleção na Editora Paz e Terra. Houve uma apresentação do artigo “Os ardis do trabalho” de José Arthur Gianotti no Museu Nacional, acompanhado de Eunice Durham e F. H. Cardoso em 1975 como parte dessas discussões.

Horizontes Antropológicos, Porto Alegre, ano 19, n. 39, p. 435-457, jan./jun. 2013 
Começaram aí os trabalhos a terem uma certa divulgação. Teve a dissertação da Lygia que de algum modo era bem anterior [defendida em 1971; publicada em 1978] a esta leva seguinte, mas depois veio a dissertação do José Sergio, depois Beatriz, Afrânio, ${ }^{13}$ depois essa geração mais nova e o grupo foi crescendo, né, alguns não necessariamente orientados por mim, mas pela Lygia.

Mas antes desse crescimento houve períodos de crise. Num determinado momento houve uma crise muito grande no PPGAS [MN/UFRJ]. O PPGAS esteve para fechar, porque foi encerrado o financiamento da Fundação Ford que deu partida ao Programa e que foi de agosto de 1968 até 1973 . Naquele momento cogitamos de ir para outras universidades. O Programa entrou num regime de contenção. Alguns de nós davam aula também em outras universidades, a Lygia dava aula na PUC-RJ, eu dei aula na UFMG [Universidade Federal de Minas Gerais]. José Sergio trabalhava como economista na Finep, assim como o Afrânio. Mas nós continuamos com as nossas discussões e lutamos para obter meios para continuar nossas pesquisas. Então eu consegui um projeto individual pela Fundação Ford, "Sistemas de distribuição e estruturas de poder”, o que me permitiu incorporar mais alguns alunos à equipe. Ao mesmo tempo o núcleo mais antigo da equipe elaborou um projeto maior que submetemos ao Social Science Research Council (SSRC) que tinha aberto um edital. Então na época se fez um projeto, e esse projeto dava continuidade exatamente à pesquisa sobre as transformações da plantation canavieira.

O projeto foi aprovado no mérito e alguns técnicos manifestaram um grande entusiasmo. Mas consideraram que eu não tinha então currículo para dirigir um projeto daquelas dimensões. Sugeriram que o projeto fosse diminuído e que eu o coordenasse, mas associado a um pesquisador americano que estava interessado no Brasil. Nós recusamos. O mesmo projeto foi apresentado ao Banco Mundial e teve parecer favorável nas instâncias técnicas. Mas para ser implementado o projeto precisava do aval de autoridades do Ministério do Planejamento e uma autoridade abaixo do ministro o vetou. Essa discussão foi levada ao conhecimento do presidente da Finep de então, José Pelúcio Ferreira, instituição onde Sergio Leite Lopes e Afrânio Garcia trabalhavam. Pelúcio se interessou em financiar o projeto. Ele estimulou então

13 Ver Leite Lopes (1976), Heredia (1979), Garcia Jr. (1983). 
uma articulação entre Finep, Ipea [Instituto de Pesquisa Econômica Aplicada] e IBGE (onde o Isaac Kerstenetsky nos dava também um grande apoio), e deles conosco. Depois de uma série de conversas com técnicos dessas instituições, vimos que eles tinham críticas ao próprio governo e estavam preocupados com as questões de emprego, distribuição de renda e migrações. Entramos nessas discussões mais macrossociais procurando fazer uma ligação entre essas questões e o que poderíamos oferecer como pesquisa, para podermos continuar aquilo que já vínhamos desenvolvendo. E para essa discussão com esses economistas críticos às políticas econômicas tínhamos a oferecer a reflexão da antropologia econômica, que então estava em pleno desenvolvimento, com as contribuições da escola de Karl Polanyi, com a divulgação dos manuscritos de Marx sobre as formações pré-capitalistas, com a literatura sobre sociedades camponesas, com a crítica ao esmagamento do campesinato nos países do socialismo real feitas por Chayanov e Tepicht então publicadas, com a discussão entre formalistas e substantivistas na antropologia econômica anglo-saxônica, com reflexos na antropologia francesa... Então, tínhamos contribuições a dar nessa discussão. Foi uma negociação relativamente lenta, mas interessante, fizemos contato com um grupo de economistas, o Cláudio Salm, o Luiz Carlos Silva, então no Ipea, enfim outros apareceram em determinado momento, então foi se delineando a efetivação do projeto.

O vínculo de Sergio Leite Lopes e Afrânio Garcia com a Finep, o seu acesso a José Pelúcio Fereira, que apoiou o projeto, foi a ponte para que Roberto DaMatta, então coordenador do Programa buscasse o apoio institucional da Finep ao PPGAS, que, com modificações, perdura até hoje. A Finep então já financiava alguns programas na área de ciências físicas e biológicas, se interessou em financiar algo na área de ciências sociais. Foi por aí, através dessa discussão sobre o Projeto Emprego, que surgiu essa ligação da Finep com o Programa. O financiamento ao Programa saiu. Assim como houve uma pressão da Finep sobre o MEC e a reitoria da UFRJ para que fossem efetivados os professores que eram do corpo do PPGAS mas eram pagos com o financiamento da Ford e não eram efetivos na UFRJ. Assim entraram para a UFRJ, em 1975, Otávio, Lygia, Francisca Keller, Tony Seeger e eu. E logo depois pudemos ter o nosso projeto aprovado, ainda em 1975. ${ }^{14}$

14 O texto desse projeto foi publicado em Palmeira et al. (1977). 
Se o nosso principal interesse com o projeto era dar continuidade aos estudos etnográficos que vínhamos realizando, aceitamos dialogar com os técnicos das entidades financiadoras sobre os temas macrossociais "emprego" e "migração". O que nos levou a abrir uma outra frente de pesquisa. Formamos uma equipe formada por mestres e mestrandos do PPGAS-MN/UFRJ (e alguns do Iuperj [Instituto Universitário de Pesquisas do Rio de Janeiro]), que fez um levantamento extensivo e com profundidade sobre os temas emprego e migração em varias bibliotecas do Rio de Janeiro.

Minha ideia era conduzir essa investigação como eu tinha realizado com a minha tese de doutorado. Só que você realizar isso coletivamente era complicado. Elaboramos um conjunto de fichas que ia do simples registro catalográfico até uma ficha analítica de textos selecionados. O que seria uma pesquisa bibliográfica convencional se transformou numa pesquisa etnográfica sui generis. Então sobretudo o José Sergio e o Alfredo Wagner logo perceberam que esse não era um trabalho de você ir lá e pegar a referencia do livro e estava resolvido. Logo perceberam que havia períodos em que o tema da migração desaparecia ao lado de períodos de grande concentração de artigos e livros sobre o tema. Partiram então para entrevistar os bibliotecários e fazer um trabalho de reflexão sobre o próprio esquema de catalogação dos fichamentos. Tomamos então conhecimento de que havia certas normas bibliográficas, mas havia mudanças de critérios que operavam por força da demanda sobre certos temas. Por exemplo os temas migração e migração interna classificavam um grande número de trabalhos até meados dos anos 1950, e pouco se encontrava nesse período relativo a questão agrária e reforma agrária; já entre 1955 e 1964 há uma espécie de inversão e o que antes se encontrava em migração se encontra em questão (e reforma) agrária. Isso foi objeto de uma reflexão de Alfredo Wagner e Zé Sergio. ${ }^{15}$ Outro resultado desse trabalho nas bibliotecas foi o que Alfredo e eu produzimos sobre a gênese ideal do conceito de migração. ${ }^{16}$ Enfim, esse projeto, que chegou a contar com cerca de 20 pesquisadores, deu muitos frutos, teses, dissertações que depois foram publicadas, e muitos manuscritos que estão aí nos arquivos, alguns dos quais a serem recuperados e publicados. O próprio Afrânio vem pesquisando esses

15 Ver Almeida e Leite Lopes (1977).

16 Ver Almeida e Palmeira (1977). 
arquivos para fazer uma avaliação desses trabalhos; e jovens pesquisadores podem encontrar matéria-prima para seus trabalhos, etnográficos ou de história social da ciência social...

O lado propriamente etnográfico do projeto representou uma extensão do que já vínhamos fazendo na região canavieira de Pernambuco, para as áreas de cana dos estados vizinhos de Alagoas e Paraíba. Nesses estados os tabuleiros, antes considerados imprestáveis para o cultivo da cana, estavam sendo cobertos por esse cultivo devido a novos usos de adubos, fertilizantes e irrigação. A exemplo de Pernambuco isso significava a expulsão de moradores e pequenos agricultores. Ao lado disso investimos também no conhecimento da pequena agricultura no Agreste e das grandes fazendas de gado e algodão que continuavam existindo no sertão desses três estados. Por outro lado, a preocupação com a indústria e com as cidades em crescimento nos levaram a tentar confrontar essas experiências - baseadas em trabalhos como o de Sergio Leite Lopes sobre operários das usinas açucareiras e o de Rosilene Alvim ${ }^{17}$ sobre 0 artesanato do ouro no Cariri cearense - com investigações em outros tipos de indústria e o chamado mercado informal em áreas metropolitanas, onde a presença de trabalhadores de origem rural era significativa. Após dois surveys, o primeiro dos quais cobrindo além de Pernambuco, Alagoas e Paraíba também o Cariri cearense e o sul do Piauí, escolhemos as áreas a serem trabalhadas.

Do lado urbano-industrial Sergio Leite Lopes e Rosilene Alvim partiram para o estudo da indústria têxtil de Paulista, que apresentava características de uma cidade-fábrica numa área semirrural que fazia parte de um império industrial com extensões comerciais em todo o país. O primeiro com a história do trabalho industrial, a segunda com as características das famílias operárias provenientes de uma migração de origem rural. Luiz Antonio Machado da Silva, então no Iuperj, deu continuidade aos seus trabalhos anteriores concentrando-se no estudo do mercado informal de trabalho em Recife. E um grupo de alunos mestrandos da equipe, trabalhando em torno dos mesmos temas, dividiu-se entre Recife e Campina Grande. ${ }^{18}$

No que diz respeito à área rural, enquanto em Pernambuco eu mesmo e Lygia Sigaud (agora voltada para o estudo dos trabalhadores da rua) demos

\footnotetext{
17 Ver Alvim (1979).

18 Ver Leite Lopes et al. (1979).
} 
sequência aos projetos anteriores, e novos alunos eram incorporados ao projeto, ${ }^{19}$ Beatriz Heredia partia para o estudo das transformações socioespaciais da plantation canavieira em Alagoas, enquanto Afrânio e Marie-France Garcia investiram no brejo paraibano. Afrânio ocupou-se sobretudo das migrações para o Sudeste do país e suas repercussões na área estudada, enquanto Marie-France desdobrava seu trabalho sobre o bacurau para as feiras da região. Na frente sertaneja, Eliane Cantarino, Alfredo Wagner e Neide Esterci estudaram fazendas de gado e algodão, a primeira no sertão paraibano e os dois últimos no Ceará. ${ }^{20}$

O que dissemos acima já dá uma ideia da maneira como esses trabalhos foram conduzidos. Acho que está claro que em todas essas experiências trabalhamos em grupo, quer nas nossas discussões teóricas, quer em campo. Se houve momentos em que pesquisadores estiveram sozinhos em campo, na maior parte das vezes trabalhamos em locais diferentes, com uma certa proximidade, nos mesmos períodos. E sempre procuramos nos manter em contato. Em algumas das idas a campo nos reuníamos a cada 15 dias em Recife, para sabermos do andamento da pesquisa de cada um, trocarmos informações e nos ajudarmos no enfrentamento das dificuldades e dos imprevistos da vida real. Algumas vezes chegamos mesmo a nos dar umas "férias", onde combinávamos algum lazer com a discussão de resultados de campo (como por exemplo um carnaval na Ilha de Itamaracá em fevereiro de 1972). Além disso houve certas ocasiões concentradas trabalho coletivo simultâneo, quando da aplicação de questionários nas feiras, ou quando de visitas coletivas a usinas. Por outro lado todo esse esforço de pesquisa se passou numa época de forte repressão no país, e mais do que nunca se colocava para os pesquisadores a preocupação de não serem atingidos pela repressão, mas sobretudo que aqueles que estavam sendo estudados não o fossem.

A primeira vez que eu entrei em Pernambuco, no dia 2 de novembro de 1969, nós atravessamos a fronteira, fomos de carro eu e a Lygia numa Rural Willys aqui do Programa (o PPGAS tinha uma Rural com tração nas quatro

${ }^{19}$ Além de Leilah Landim e Doris Rinaldi, já mencionadas, Regina Novaes estudou pequenos agricultores do Agreste, explorando sua filiação religiosa evangélica até então pouco estudada; ver Novaes (1978).

${ }^{20}$ Ver "Relatório final do projeto emprego e mudança sócio-econômica no Nordeste" (1977). Os estudos mencionados de Alfredo Wagner e Neide Esterci no Ceará se desdobraram depois em áreas do Maranhão.

Horizontes Antropológicos, Porto Alegre, ano 19, n. 39, p. 435-457, jan./jun. 2013 
rodas). Quando atravessamos a divisa de Alagoas com Pernambuco ouvimos pelo rádio que tinha sido assassinado o Carlos Marighela. Isso foi um choque; e havia barreiras policiais nas estradas, uma coisa pesadíssima. O clima geral do país já era pesado. Aqui no Rio, então, para a gente conversar até sobre assuntos meramente intelectuais você tinha que tomar cuidado porque qualquer reunião podia ser denunciada e coisas desse tipo. Quando planejávamos essa ida ao interior de Pernambuco em 1969 todo mundo dizia: "Não, você não vai encontrar nada, você vai ser preso, os sindicatos ficaram todos pelegos, não tem mais nada e tal.” E quando eu chego no interior de Pernambuco eu encontro manifestações em massa, 200, 300 trabalhadores na porta de juntas trabalhistas exigindo seus direitos. Várias usinas tinham falido. A federação dos trabalhadores rurais (Fetape [Federação dos Trabalhadores na Agricultura do Estado de Pernambuco]) estava caindo em cima dos proprietários exigindo que em 1969 fosse depositada a parte do INPS das usinas, que tinha sido recentemente estendida aos trabalhadores canavieiros, que elas não estavam efetuando; a federação foi atrás desses direitos. Antes que acusada de subversiva, a federação acusava ao contrário os patrões por estarem desrespeitando a lei. A luta de classe continuava acesa, com paradas de trabalho quase todo dia, alguns sindicatos muito atuantes. A repressão pesada lá não veio logo com o AI-5, viria em 1971 e 72, aí começaram intervenções em massa nos sindicatos.

Mas a essa altura, o esquema era um pouco esse, você tinha certos lugares onde a comunidade era de fato uma base muito sólida do sindicato local. Lá onde a Beatriz trabalhou, em Carpina, e onde eu trabalhei também parte do meu tempo, havia uma comunidade dessas, que era a base do sindicato. O Ministério do Trabalho fechou os sindicatos em 1964, na primeira folga que deu o pessoal reorganizou o sindicato. Fecharam de novo em 1971, mas rapidamente o sindicato foi reorganizado. Então cada vez que dava a coisa ressurgia porque o sindicato estava basicamente ligado a uma comunidade. Não foi por acaso que alguns de nós nos vinculamos ao movimento sindical. Eu pessoalmente fiquei muitos anos como assessor da Contag [Confederação Nacional dos Trabalhadores na Agricultura], porque em plena ditadura abria uma perspectiva de luta de massa.

Então, como ia dizendo, logo num primeiro momento uma coisa fundamental era a segurança da pesquisa, o problema de segurança era seríssimo, se aparecesse qualquer pessoa de fora nas áreas que frequentávamos, ela era 
vista como se fosse alguém da guerrilha querendo se estabelecer. Logo que entrei em Palmares acabava de ser preso uma pessoa que diziam ser da AP [Ação Popular], que estava vivendo como camponês para fazer um trabalho político. Essa ação repressiva atingiu também alguns trabalhadores rurais. Então nós, como pessoas de fora, tínhamos que ser extremamente cuidadosos. Carregávamos uma credencial pomposa que o Roberto Cardoso inventou, dirigida “Às autoridades brasileiras”. Então chegávamos na cidade e a primeira coisa era ir falar com o prefeito, e depois saíamos procurando as organizações formais existentes, patronais, religiosas, etc.; para depois colarmos nos sindicatos de trabalhadores rurais. Muitos prefeitos sugeriam que nos apresentássemos à delegacia de polícia e nós nos recusávamos, não queríamos assunto com eles. Numa das cidades tinha um delegado que todos diziam que esteve envolvido na repressão, que seria um torturador (depois foi eleito deputado), então a gente não queria assunto com esse cara.

Nas visitas às organizações patronais, abrimos a possibilidade de termos algum contato com os proprietários. Pedíamos que nos indicassem com quem conversar. $\mathrm{O}$ que nos abria a possibilidade, mesmo que formal, de acesso à classe patronal. Dizia-se em Pernambuco que os engenhos tinham a porteira fechada. O acesso direto aos moradores era impraticável. Mas se aos moradores era possível ter acesso nas sedes dos sindicatos, com os barracões, meu objeto de pesquisa, a coisa era mais complicada. Como eu vou estudar o barracão de fora do engenho? A solução que encontramos foi elaborar um questionário com muitas perguntas quantitativas e com códigos nas margens, dando impressão de grande cientificidade. Uma amostra a ser selecionada a partir do registro de estabelecimentos que forneciam cana às usinas obtido no Instituto do Açúcar e do Álcool. Mais do que a preocupação quantitativa, o que estava em jogo era "atravessar a porteira dos engenhos” e ter um acesso direto aos barracões. A estratégia era fazer com que enquanto um pesquisador entrevistava o barraqueiro o outro conversava com os trabalhadores. Estes costumavam se reunir no final da tarde depois do dia de trabalho, na porta dos barracões. Mas mesmo esses artifícios não resolviam todos esses problemas. A nossa amostra teve que ser ajustada várias vezes. ${ }^{21}$ Havia usinas que não

${ }^{21}$ Essas alterações foram registradas em cadernos de procedimentos, explicitando todas as pequenas decisões tomadas e por quê, que ainda pretendo editar para uso dos estudantes. 
abriam a porteira em hipótese alguma. Era o caso da Usina Estreliana, onde um pouco antes do golpe havia ocorrido um massacre de trabalhadores. ${ }^{22}$

No caso dos engenhos particulares nossa entrada passava por uma conversa prévia com o senhor de engenho. No caso das usinas o contato era feito com o gerente geral ou em alguns casos com os próprios usineiros, que designavam um funcionário para nos acompanhar. Houve situações mais ou menos tensas: numa usina em Goiana [Mata Norte de Pernambuco], havia um funcionário truculento e foi difícil lidar com isso. Mas em geral, chegando ao barracão, gerávamos uma certa alegria entre os trabalhadores porque achavam que se tratava de uma fiscalização em cima do barracão. Os barraqueiros admitiam que seus preços eram $20 \%$ maiores do que na cidade, mas os trabalhadores sabiam que eram muito maiores do que isso. Então vinha aquela curiosidade e outros trabalhadores iam espontaneamente se aproximando. Às vezes quando eu estava entrevistando o barraqueiro um dos trabalhadores se aproximava criando a situação de que ele pudesse contar a sua própria história. Eram situações que obrigavam o barraqueiro, por uma espécie de competição implícita que se estabelecia na hora, a falar de sua própria história. Havia situações em que o barraqueiro suspendia a entrevista para abrir uma nova conta para o trabalhador endividado. E aí, a gente ia etnografando toda a situação. Mais do que as respostas às questões formais, as observações que fazíamos no verso desses formulários eram o principal.

A grande questão era que fazer pesquisa no momento em que o Brasil se encontrava, você corria um perigo muito grande - não só o pesquisador, que algumas pessoas sofreram interpelações, o Gatti foi um - mas você podia criar problemas para seus informantes, para o grupo com que você estava lidando. Então tinha que ter um cuidado permanente. Por exemplo, depois de um longo período em que estivemos Vera Echenique e eu numa hospedaria das irmãs do Sagrado Coração na Mata Norte de Pernambuco, já no Rio, de volta, recebi um telefonema tenso do presidente do sindicato pedindo para enviar uma cópia da nossa credencial de pesquisa porque o Dops [Departamento de Ordem Política e Social] tinha ido tomar satisfações com as irmãs a nosso respeito. Era preciso ter um cuidado permanente. Era indispensável, quando em campo, exportar o material coletado o mais rápido possível. Precisávamos estar

${ }^{22}$ Conferir Carneiro e Cioccari (2011, p. 67-69). 
atentos para não colocarmos no caderno de campo informações que pudessem ser comprometedoras para informantes e pesquisadores. Era comum usarmos nos diários alusões indiretas pois o material representava perigo. Lygia Sigaud e eu por exemplo íamos a Recife com alguma frequência para passarmos os cadernos a uma parente dela que morava nessa cidade, e ela enviava pelo correio para o Rio. Era comum entre os pesquisadores procedimentos equivalentes para a preservação do material e dos informantes. O que significava mais trabalho de reconstituição no Rio.

Mas acho que valeu a pena.

\section{Referências}

ALMEIDA, A. W.; LEITE LOPES, J. S. Na poeira das bibliotecas: reflexões sobre as categorias emprego e migração na bibliografia brasileira. In: RELATÓRIO FINAL do Projeto Emprego e Mudança Sócio-econômica no Nordeste: vol. 1. Rio de Janeiro: PPGAS-MN/UFRJ, 1977. Manuscrito.

ALMEIDA, A. W.; PALMEIRA, M. G. S. A invenção da migração. In: RELATÓRIO FINAL do Projeto Emprego e Mudança Sócio-econômica no Nordeste: vol. 1. Rio de Janeiro: PPGAS-MN/UFRJ, 1977. Manuscrito.

ALVIM, R. A arte do ouro: um estudo sobre os ourives de Juazeiro do Norte. Brasília: UnB, 1979. (Pesquisa Antropológica, 19).

CARNEIRO, A.; CIOCCARI, M. Retrato da repressão política no campo: Brasil 1962-1985. 2. ed. Brasília: Ministério do Desenvolvimento Agrário, 2011.

DAVIS, S. H. La tierra de nuestros antepasados: estudio de la herencia y la tenencia de la tierra en el altiplano de Guatemala. La Antigua: Centro de Investigaciones Regionales de Mesoamérica; South Woodstock: Plumsock Mesoamerican Studies, 1997.

ENTREVISTA com Luiz Antonio Machado da Silva. Revista Habitus, v. 8, n. 2, p. 142-147, 2010. Disponível em: <http://www.habitus.ifcs.ufrj.br/ojs/ index.php/revistahabitus/article/view/109/135>. Acesso em: 30 ago. 2012. 
GARCIA, M.-F. O Bacurau: étude de cas d'un marché situé dans une usina. Dissertação (Mestrado em antropologia Social)-Museu Nacional/ Universidade Federal do Rio de Janeiro, Rio de Janeiro, 1977.

GARCIA JR., A. Terra de trabalho: trabalho familiar de pequenos produtores. Rio de Janeiro: Paz e Terra, 1983.

GATTI, L. M.; ECHENIQUE, V. M. M. Relaciones sociales en una feria. Revista del Instituto de Antropología, Córdoba: Universidad Nacional de Córdoba, n. 5, p. 59-66, 1974.

GENESTOUX, P. C. du. Le Nord-est du sucre. Thèse de troisième cycle présentée à la Faculté de Droit et Sciences Economiques de Paris, 1967.

HEREDIA, B. A morada da vida. Rio de Janeiro: Paz e Terra, 1979.

LANDIM, L. A Cooperativa do Trabalhador: diferenciação social e organização camponesa. Dissertação (Mestrado em Antropologia Social)-Museu Nacional/ Universidade Federal do Rio de Janeiro, Rio de Janeiro, 1978.

LEITE LOPES, J. S. O vapor do diabo: o trabalho dos operários do açúcar. Rio de Janeiro: Paz e Terra, 1976.

LEITE LOPES, J. S. et al. Mudança social no Nordeste: a reprodução da subordinação: estudos de trabalhadores urbanos. Rio de Janeiro: Paz e Terra, 1979.

NOVAES, R. Os escolhidos de Deus: doutrina religiosa e prática social. Dissertação (Mestrado em Antropologia Social)-Museu Nacional/ Universidade Federal do Rio de Janeiro, Rio de Janeiro, 1978.

PALMEIRA, M. G. S. Nordeste: mudanças políticas no século XX. Cadernos Brasileiros, v. 39, 1966.

PALMEIRA, M. G. S. Latifundium et capitalisme au Brésil: lecture critique d'un débat. Thèse de troisième cycle de Sociologie présentée à la Université de Paris 5, 1971. 
PALMEIRA, M. G. S. et al. Emprego e mudança sócio-econômica no Nordeste. Anuário Antropológico/76, p. 207-292, 1977.

PALMEIRA, M. G. S. Saudação ao Professor Otávio Velho em razão da concessão do título de Professor Emérito da Universidade Federal do Rio de Janeiro. Numen: Revista de Estudos e Pesquisa da Religião, v. 9, n. 2, p. 9199, 2006. Disponível em: <http://www.editoraufjf.com.br/revista/index.php/ numen/article/view/680/582>. Acesso em: 30 ago. 2012.

RELATÓRIO FINAL do Projeto Emprego e Mudança Sócio-econômica no Nordeste: vol. 1: parte rural. Rio de Janeiro: PPGAS-MN/UFRJ, 1977. Manuscrito.

RINALDI, D. A terra do santo e o mundo dos engenhos: estudo de uma comunidade rural nordestina. Dissertação (Mestrado em Antropologia Social)-Museu Nacional/Universidade Federal do Rio de Janeiro, Rio de Janeiro, 1978.

RINGUELET, R. R. Migrantes estacionales de la región del agreste del Estado de Pernambuco. Dissertação (Mestrado em Antropologia Social)-Museu Nacional/Universidade Federal do Rio de Janeiro, Rio de Janeiro, 1977.

SIGAUD, L. M. A nação dos homens. Anuário Antropológico/78, p. 13-116, 1979a.

SIGAUD, L. M. Os clandestinos e os direitos. São Paulo: Duas Cidades, 1979b.

VELHO, O. Capitalismo autoritário e campesinato. São Paulo: Difusão Européia do Livro, 1976. 